\title{
Was it merely contentious or were there casualties? \\ Metaphorical Framing in Local and International News Reporting
}

Jill Hallett* \& Marta Degani**

\begin{abstract}
This study investigates the role of metaphor in news reporting by focusing on one US event, the historic 2012 Chicago Teachers Union (CTU) strike and compares its coverage in local and international English-language news. We are particularly interested in finding out how a news story, like the CTU strike, with strong localised metaphorical discourses, can be presented to readers outside the local and national cultural speech communities. In this sense, the research also contributes to understanding how the media can affect the portrayal and reception of important social events by using metaphorical language in newspaper coverage. Employing a qualitative research approach of Discourse Analysis and drawing on Critical Metaphor Analysis (Charteris-Black 2004), a particular focus is put on salient metaphor use across contexts (Goatly 2002) and on the role of reporters and news wire services in the presentation of facts. The findings indicate that both local and international news chiefly rely on two types of metaphor, JOURNEY and CONFLICT. Notable differences were found in how the CONFLICT metaphors were expressed in the two contexts.
\end{abstract}

Key words: metaphorical framing, local and international news reporting, Chicago Teachers Union strike 2012, Critical Metaphor Analysis, JOURNEY metaphors, CONFLICT metaphors

\footnotetext{
* Northeastern Illinois University, Literacy Education and Secondary Education; University of Illinois at Chicago, Linguistics and Curriculum \& Instruction; jm-hallett@neiu.edu

** University of Klagenfurt, English Department; marta.degani@aau.at; University of Verona, Department of Foreign Languages and Literatures; marta.degani@univr.it
} 


\section{Introduction}

Media are responsible for the transmission of knowledge across languages and cultures worldwide, and their discourses have the potential to shape opinions, influence attitudes, and trigger behavioural patterns (see Downing et al. 2004). Media construct social meanings and allow for their wide circulation in diversified contexts. They also decide which aspects of social reality to make into an issue of general concern, by providing not just a selection of information to be made available to the public, but also by imposing an order and hierarchical structuring to it. Media establish priorities by foregrounding and backgrounding information, by giving voice and hence salience to certain issues while at the same time silencing others. Furthermore, they function as historical depositories of information since their records represent the tangible counterparts of volatile and elusive collective memories about facts.

In the literature, this capacity of mass media to transform facts into 'discursive events', which may support political or economic interests and favour particular social groups by giving prominence to their worldviews and ideological leanings, is generally referred to as their framing potential (see e.g. Lakoff 1996, 2014; Entman 1993; Gamson 1992; Reese et al. 2003). News discourse has a vast array of framing devices at its disposal, which may be expected to affect reception and guide understanding by the public (see Fairhurst and Sarr 1996, Gamson and Modigliani 1989, Van Gorp 2005). Journalists can adopt different framing techniques when reporting on facts, such as selecting a topic, planning on headlines, leads and concluding statements, choosing sources, deciding to report, quote or paraphrase, and using images to support the argumentation. While these important strategies have more to do with structural (or graphic, in the case of images) components of journalistic texts, other framing devices such as keywords, repetitions, slogans, and metaphors affect journalistic contents more directly. The use of metaphor, in particular, seems to be pervasive in news reporting, where it plays a central framing function. As Semino $(2008,91)$ points out, metaphor

has consequences for how a particular issue is 'framed' or structured, which aspects are foregrounded and which are backgrounded, what inferences are facilitated, what evaluative and emotional associations triggered, what courses of action seem to be possible and so on.

Previous studies show that demonstrations, revolts, and situations of social unrest are framed metaphorically in media discourse, and that metaphor can function as an important ideological framing device in their media representations (Fridolfsson 2008; Hart 2014a, 2014b, 2017). Research also shows that metaphors are connected to culture and 
their use as well as their implications can change depending on the cultural contexts in which they circulate (Kövecses 2005).

Fitting into this previous research, the study presented here also contributes to understanding how the media can affect the portrayal and reception of important social events by using metaphorical language in newspaper coverage. The study investigates the role of metaphor in news reporting by focusing on one US story about social protesting in education, the historic 2012 Chicago Teachers Union (CTU) strike and comparing its coverage in local and international English-language news. We are particularly interested in finding out how a news story, like the CTU strike, with strong localised metaphorical discourses, can be presented to consumers outside the local and national cultural speech communities. When metaphor is analysed from a comparative local vs. international point of view, a range of questions arises: what metaphors are employed in international English-language news coverage of one US local story, and how does this metaphor use compare to coverage in situ? How do news wire services use metaphor in international English-language coverage of the same story?

The present study employs a qualitative research approach of Discourse Analysis. It considers salient metaphor use across contexts (Goatly 2002) and scrutinises the role of reporters and news wire services in the presentation of facts. The study is based on two main working hypotheses. First, we hypothesise that the rootedness of the reported event, the 2012 CTU strike, in a micro-cultural context will entail a different portrayal of the same story in local vs. international news. Our second hypothesis is that, because of the pervasiveness of metaphor in media discourse, metaphorical depictions will characterise the reporting of the event in both the local and the international news.

On the back of these working hypotheses, the study will explore whether there are differences in metaphor usage when comparing local vs. international reporting of the CTU strike, and, in case differences emerge, whether they can be related to the type of target readership and their assumed expectations.

The paper will first review the literature and the theoretical framework of reference (section 2). The discussion will then focus on a range of methodological concerns of the research (section 3). This will introduce the results of the data and their critical discussion (section 4). In the conclusion (section 5), the major findings will be summarised and commented on, and some implications of the study will be presented. 


\section{Theoretical Framework}

Our study is couched in a long tradition of linguistic research on discourse and metaphor in the media. In the fields of sociology and media and communication studies, a variety of theories are used that approach media discourse from the vantage points of agendasetting, priming, and framing (see e.g. Entman 1993, Gamson 1992, McCombs 1997, McCombs and Shaw 1972, Weaver 2007). While these theories explore the role of the media in the construction of forms of discourse that are socially shared, a linguistic approach allows for a close analysis of language that can account accurately for the subtle meanings transmitted by media discourse, especially when it comes to evaluating the use of metaphorical language. In line with a linguistic approach, our investigation is guided by the insights of Critical Discourse Analysis and Critical Metaphor Analysis.

This study shares the general approach of Critical Discourse Analysis (see e.g. Fairclough 1995, 1999; Wodak 2005). It looks at language in terms of discursive practices, has a critical eye on how contexts can affect language use, and questions textual representations that are influenced by producers as well as target receivers and can strategically transmit submerged ideologies.

In line with Critical Metaphor Analysis (Charteris-Black 2004), we consider metaphor as a conceptual and linguistic phenomenon that can act as a powerful means of persuasion or manipulation, especially when used by the media to prioritise one understanding of reality over others, and hence subtly influence processes of decision-making and subsequent, related behaviours. Beyond recognising the cognitive dimension intrinsic to metaphor, the critical analysis conducted here emphasises the strategic use of metaphor as a rhetorical device for projecting particular views and obtaining consensus. The actual interpretation of metaphor adopted in this study follows Charteris-Black, who defines metaphor as "any word or phrase that causes semantic tension at the linguistic, cognitive and pragmatic levels resulting in a shift in domain use and having persuasive potential of influencing opinions and judgements" (2004, 21). Accordingly, this study analyses metaphor in its contexts of use and explores the potential motivations for its use. Our analysis of metaphor in news reporting is also based on the postulated distinction between "linguistic metaphors" or "metaphorical expressions" and "conceptual metaphors" as their underlying image-schema structures or cross-domain mappings (Lakoff and Johnson 1980). Still in line with Critical Metaphor Analysis, the approach taken is corpus-based since the analysis is carried out on authentic textual data, a large number of newspaper articles in English from different sources worldwide.

Previous studies have already explored the strategic and ideological uses of metaphor in the media. Charteris-Black (2017), for instance, discusses how media recurrently use FIRE metaphors to talk about protest and protesters, and how this can trigger negative 
evaluations of the event and the people involved because of our experientially grounded understanding of fire as a destructive force. Hart (2017) examines media coverage of the historic British Miners' Strike of 1984-1985 to unveil media strategies of (de)legitimisation. To that aim, he considers the potential ideological functions of one specific metaphorical framing of the strike as a WAR between the State and the National Union of Miners. Johnson (2007) scrutinises the various metaphors employed by the media in the United States with the covert aim of legitimising the "English-Only" movement and justifying "Proposition 203: English for the children".

A number of studies have also examined how the media rely on culture-bound types of metaphors as discursive strategies that can engage or entice their audiences. Media outlets, for instance, have been observed to employ culturally salient metaphors to make consumers feel more involved in political discourse (Archakis and Tsakona 2010). Mass-mediated metaphor is highly culture-bound, evoking frames salient to local contexts (Medhurst and DeSousa 1981, Hallett and Hallett 2012) and perpetuating them through repetition (Semino 2008). With respect to metaphor in the media, "a combination of repetition and recurrence can lead to the formation of 'chains' of connected metaphorical expression in texts" (Semino 2008, 24).

While the research cited here considers metaphor in the media within shared cultures, it does not give sufficient attention to the intersections of metaphor and media in English both within and outside its local source. This aspect will be addressed and critically discussed in the present study.

\section{Methodology}

\subsection{Research Design}

Our research uses an approach of Discourse Analysis to local and international Englishlanguage news coverage of one US story, the historic 2012 Chicago Teachers Union (CTU) strike. It considers salient metaphor use across contexts (local vs. international) and scrutinises the role of reporters and news wire services in the (re)presentation of facts. Even though some numerical data are provided, the orientation of the research is chiefly qualitative in the sense that it is descriptive and interpretative, in line with Critical Discourse Analysis and Critical Metaphor Analysis.

\subsection{Research Context}

There are a number of factors in discourse around education in Chicago that were relevant to the September 2012 CTU strike. Most significantly, the 2012 strike was the 
first in two and a half decades, after tumultuous labour negotiations resulted in a series of Chicago teacher strikes in the 1980s.

Major stakeholders in the 2012 scenario, aside from the teachers, students, and parents, included Chicago mayor Rahm Emanuel and CTU leader Karen Lewis. Emanuel became Chicago's mayor after a stint as President Barack Obama's Chief of Staff. As Emanuel is a White northsider from an affluent suburb, and many of his efforts as mayor focused on affluent, largely White areas of the city, he was considered an outsider by many Chicagoans. The fact that he sent his own children to private school did not help this image. Karen Lewis is a former Chicago Public Schools high school teacher and was President of the Chicago Teachers' Union from 2010-2018. She is African American and lives on the south side of Chicago, which has historically been populated by Black and Brown people. Thus, Emanuel and Lewis are polarised, which leads to proxy polarisation by union members, parents, administrators, Chicago residents, and other education stakeholders.

The timing of the strike occurred amid escalating violence among Chicago youth, and discussions at the district level about teacher merit pay, longer school days, 50-100 potential school closings (mostly in Black/ Brown neighbourhoods), and an increasing establishment of charter schools. The CTU voted to strike for the first time in 25 years, with teachers and students out of school from September 10-18, 2012.

\subsection{Data Collection and Analysis Procedure}

A LexisNexis search was conducted for coverage by English-language international news outlets during September 2012 (inclusive of the strike dates and surrounding context), using the keywords "Chicago teachers". Twenty-three articles were retrieved (four duplicates or near duplicates), amounting to 7,605 words in total and covering a time span from September 12, 2012 to September 20, 2012. Data were coded for name of paper, location, wire service, date, headline, linguistic metaphor in context, metaphor user (reporter, quoted speaker, etc.), and type of underlying conceptual metaphor. Table 1 provides an overview of the international papers (both wire and non-wire) retrieved from the search along with the number of articles addressing the issue of the CTU strike. 


\begin{tabular}{|c|c|c|c|c|}
\hline \multicolumn{2}{|l|}{ Non-wire papers } & \multicolumn{3}{|c|}{ Wire papers } \\
\hline Paper & Stories & Paper & Service & Stories \\
\hline China Daily European Edition & 4 & Nanaimo Daily News, BC & News Services/Reuters & 3 \\
\hline The Independent, London & 1 & Times of Oman & AFP & 2 \\
\hline & & New Indian Express & $\mathrm{HT}$ & 1 \\
\hline & & Right Vision News, Karachi & HT & 1 \\
\hline & & Korea Times & Scripps & 1 \\
\hline & & The Times and Transcript, NB & Reuters & 3 \\
\hline & & The National Post, Canada & Reuters & 1 \\
\hline & & The Times, London & $\mathrm{AP}$ & 1 \\
\hline & & The Times, Ireland & $\mathrm{AP}$ & 1 \\
\hline & & The Irish Times & Bloomberg & 1 \\
\hline & & Waikato Times, NZ & Fairfax New Zealand & 1 \\
\hline & & The Southland Times, NZ & Fairfax New Zealand & 1 \\
\hline & & Taranaki Daily News, NZ & Fairfax New Zealand & 1 \\
\hline
\end{tabular}

Table 1: International coverage of the CTU strike

Four articles were duplicates or near duplicates: The Times London and The Times Ireland, 9/14/2012 (fully identical; same publisher); The Times and Transcript, NB and Nanaimo Daily News, BC, 9/15/2012 (mostly duplicate; same wire); Taranaki Daily News, NZ, 9/18/2012 with China Daily, Europe, 9/17/2012 (partial); and Waikato Times, NZ and The Southland Times, NZ, 9/20/2012 (identical except headline; same wire), which shared a few lines with Nanaimo Daily News in Canada.

For the local news coverage of the CTU strike, data were gathered exclusively from the daily newspaper Chicago Tribune, since it is Chicago's newspaper with the highest readership. The articles were obtained via ProQuest and amount to 118, with a time span from September 1, 2012 to September 30, 2012, and a total length of about 98,200 words. In order to allow for a quantitative comparison between the two data sets, 19 articles were selected among the pool provided by the Chicago Tribune. This representative sample includes articles that are among the longest and that are distributed throughout the different weeks of September 2012. These data were coded for headline, date of publication, linguistic metaphor in context, underlying conceptual metaphor, and metaphor user.

Both data sets were investigated for metaphors. Figurative uses of words were identified in line with the Metaphor Identification Procedure (MIP) theorised by the Praggle- 
jaz group (2007). The analysis was three-fold. It was aimed at 1) identifying metaphorical linguistic expressions in the articles, 2) postulating underlying conceptual metaphors, and 3) reflecting on potential strategic uses and effects of the identified metaphors. Results from the two data sets were then compared, mostly qualitatively. International stories were also analysed qualitatively for patterns of metaphor use in reporting by wire service or by newspaper.

\section{Results and Discussion}

It was hypothesised that the CTU strike would be portrayed differently in local vs. international news given the fact that it originated in a specific cultural, social and political context, with which people outside of Chicago might not be too familiar. Given the pervasiveness of metaphor in media discourse, it was also hypothesised that metaphorical depictions of the strike would characterise the reporting of the event in both the local and the international news. The question of how metaphor was employed in the two data sets is addressed in the following sub-sections.

While many types of metaphor were present across both local and international stories (e.g. GAME, BUILDING, DISEASE, WATER, REIFICATION, and PERSONAIFICATION metaphors), two metaphor types prevailed across both data sets: JOURNEY and CONFLICT (see Ritchie 2013 in which CONFLICT subsumes WAR metaphors).

In Conceptual Metaphor Theory, CONFLICT metaphors have been discussed since the very beginning as extremely prominent types of metaphors (see Lakoff and Johnson 1980). Any process with a temporal unfolding can be metaphorically conceptualised as a JOURNEY through space that involves participants/travellers, vehicles, stages, distance, speed, a direction, a destination, and potential obstacles on the way. In all of the analysed articles, the CTU strike as a stoppage of activities that lasted for more than a week and involved various stakeholders and negotiations, lent itself easily to metaphorical depictions in terms of a journey.

In a similar fashion, research has demonstrated that WAR metaphors are very common in all kinds of political discourse (Semino 2008), health (Demmen et al. 2015; Semino et al. 2017), and business (Koller 2005). This discursive circulation of WAR metaphors in various domains has to do with the vast applicability of the WAR frame. As Semino points out, "any domain of experience that involves difficulties, danger, effort and uncertain outcomes" (2008: 100) is likely to be metaphorically conceptualised through a WAR frame. Furthermore, framing an issue in terms of a metaphorical WAR involves certain rhetorical effects that can cause evaluative and affective reactions. In this respect, 
Semino (2008) remarks that "the use of WAR metaphors tends to dramatize the opposition between different participants in politics (who are constructed as enemies), and to emphasize the aggressiveness and seriousness of political debates, conflicts or elections" (100). Adding yet a further perspective, Flusberg et al. (2018) discuss WAR metaphors as shared cultural frames that convey a message efficiently and produce an effect of urgency toward action for the receiver.

Closer to our current investigation, previous research has also shown that forms of political protest and demonstration are often rendered in the media by relying on WAR metaphors. Fridolfsson (2008), for instance, conducted an analysis of the framing effects of WAR metaphors in anti-globalisation protests in Gothenburg, while Hart (2014a, 2014b) carried out two studies about the same type of metaphors in media reports of the 2009 G20 protests and the 2010 Student Fee protests. Research about strategic and framing effects of metaphors in media reporting of strikes features in two other relevant studies: Hart (2017) and Ezeifeka (2013).

Hart (2017) explains potential motivations behind the use of WAR metaphors to describe situations of social unrest like strikes in light of the WAR frame, which allows for a reduction in complexity of the actual situation to a simple scenario having restricted goals and outcomes. According to Hart (2017), this frame is instrumental in depicting a binary opposition between two contrasting groups of actors (the aggressor/villain vs the victim) and can strategically promote an ideologically driven legitimisation of the government (the victim) coupled with a parallel (de)legitimisation of the protesters (the villains). In this sense, media discourse usage of WAR metaphors to talk (and write) about a strike can also have certain moral and ethical implications in as far as strikers are discursively demonised while the government's actions are profiled as just and necessary, and politicians might appear as the custodians of morality.

Ezeifeka (2013) scrutinises the strategic and ideological uses of conventional metaphors to describe the Nigerian Union of Teachers' strike by focusing on its portrayal in The Guardian, a privately-owned Nigerian newspaper. The analysis reveals the negative effects conveyed by a range of WAR/CONFLICT, DISEASE/ILLNESS, GAME, and SACRIFICE metaphors to depict the strike, the teachers and their salary. The investigation also sheds light on a kind of manipulative use of metaphorical language in news reporting that is liable to mask reality in its projection of elite views and biased support of power structures.

On the background of this research, the present section accounts for the specific metaphor usage characterising the local coverage of the 2012 CTU strike from the Chicago Tribune data and the international English-language coverage of the same event. The focus will be on the different linguistic instantiations of the identified conceptual metaphors 
of JOURNEY and CONFLICT. The discussion will also qualitatively compare the local and global frames for metaphor use in media coverage that emerged from the analysis. This section will conclude with a comparison between wire and non-wire coverage of the international news in terms of metaphor use.

\subsection{Metaphors in Local Coverage of the 2012 CTU Strike}

A first general observation emerging from the analysis of the articles in the Chicago Tribune is the ubiquity of metaphorical expressions in the data. Metaphor use is prolific and characterises each and every one of the investigated texts, with most articles including dozens of metaphorical expressions. Just to give two illustrative examples, the article "Strike risky for mayor, union chief" published 9/9/2012, with a word length of 1,612 words, contains 80 distinct metaphorical expressions, and the article "Parents power pivotal in walkout", published 9/16/2012, with 1,076 words, includes 59 individual linguistic metaphors.

Three other important observations need to be made here. First, JOURNEY and CONFLICT metaphors were not simply present in all articles but accounted for the most frequent types of conceptual metaphors overall. In the representative sample (19 articles, and 18,481 words in total) that was compiled to allow for a quantitative comparison to the international news data set, CONFLICT metaphors represent $35.9 \%$ of all conceptual metaphors ( $\mathrm{N}=209)$, while JOURNEY metaphors account for $23.3 \%$ of all metaphors $(\mathrm{N}=136)$.

Second, it was expected that the two major figures in the strike discussions, Mayor Rahm Emanuel and CTU President Karen Lewis, would be the source of incompatible metaphor use, potentially indicating conceptual differences with respect to education. This expectation, however, was not met. Most of the metaphor use came not in quotation or paraphrase of Emanuel, Lewis, or other stakeholders, but from the reporters. Emanuel, in particular, is quoted with very few metaphors at all. In the representative sample, $85.5 \%(\mathrm{~N}=487)$ of the metaphorical expressions come from the journalists, while only $1.8 \%(\mathrm{~N}=11)$ are reported as paraphrase or direct quote of Lewis and just 3 linguistic metaphors are attributed to Rahm. Other metaphor users in the sample include, among the most representative, mothers, fathers, teachers, CPS School Board President David Vitale, directors of colleges, and policy scholars.

The third observation is that the linguistic instantiations of the CONFLICT metaphor used in the Chicago Tribune are exceptionally graphic. Metaphors, in general, are instrumental in creating an emotional involvement (i.e. pathos) in their receivers, and to that aim they can be discursively exploited by their producers (see Semino 2008, CharterisBlack 2011). When metaphors succeed in giving rise to an effective emotional engage- 
ment, their receivers most typically respond emotionally by identifying with the point of view of the metaphor user, and often recreating the communicated feelings in an imaginative manner (see Cockcroft and Cockcroft 2014). Metaphors, therefore, can be extremely powerful in giving shape and directing people's emotions. That said, it is also reasonable to expect that the degree of engagement will vary depending on the actual wordings that verbalise a conceptual metaphor. In the Chicago Tribune data, one can find a clear tendency to verbalise the CONFLICT metaphor by choosing linguistic expressions that are remarkably vivid and pictorial, and hence likely to provoke strong reactions in the readers.

In order to substantiate further the observations that have been provided so far, the remainder of this section will offer some elucidative exemplification from the Chicago Tribune data, and comment on the expected potential effects of metaphor use in these journalistic texts by focusing on JOURNEY and CONFLICT metaphors.

In line with the general trend observed above, JOURNEY metaphors were found to be employed chiefly by reporters and only to a very small extent by Lewis and a few other stakeholders. Example (1) comes from the article "CPS leader optimistic after talks: Official: District, union close to 'endgame' with latest contract proposal" published 9/9/2012. Here, CPS School Board President David Vitale uses two Journey metaphors to describe contract negotiations with the Chicago Teachers' Union.

(1) "This is a proposal that we believe is very close to what is needed to get a deal. We have listened and we have moved dramatically on almost all of the issues."

In example (1), the structural component of the JOURNEY frame/domain that is actualised in both metaphorical linguistic expressions (in italics) is the distance between the two parties involved in the negotiation process, the Chicago Public Schools and the Teachers Union. Vitale's uses of the metaphorical wordings very close to depict his new proposal and moved dramatically to describe the decisions already taken in favour of the Teachers Union contribute to emphasising all the efforts he has already put in this process as well as his benevolent attitude in finding an agreement in such a complex negotiation. On other occasions, articles simply foreground the disagreement between the two sides involved (e.g. far apart) and the difficulty in finding viable and acceptable solutions (e.g. find their way).

While the contract talks and negotiations are frequently described as a JOURNEY, invoking a course, impasse, and burdles, Lewis and CTU members are often featured using the JOURNEY metaphor to describe the solidarity among Chicago teachers and CTU's vision of public education. This is exemplified in (2), from the 9/19/2012 article "BACK TO SCHOOL: Classes resume today as union ends walkout; Labor chief claims victory in changing evaluation, rehiring proposals; Emanuel secures longer day". 
(2) "The unity we gained is going to move us forward, and we'll continue to fight for the soul of public education.”

In this example, teacher Haley Underwood uses a JOURNEY metaphor to describe teacher unity as propelling forward a movement toward a shared goal of maintaining "the soul of public education." In this case, the metaphorical expression sustains a positive portrayal of a communal engagement, based on shared ideals and objectives, i.e. the idea that public education is rooted in a set of values that need to be preserved. Other examples of metaphorical language use that emphasise the cohesiveness among Chicago teachers and the goal-orientation of their actions include moving forward, moving up a step, paves the way, and moves together.

In addition to the examples discussed so far, the JOURNEY frame/domain lends itself to a metaphorical representation of other facets related to the strike. These comprise a potential increase in the teachers' salary schedule (moving up a step), costs for education (outpaced), reactions to the strike (mobilize, take a different journey), mistakes (took a left turn, went too far, missteps), and the duration of the strike (patbway to get back in).

In comparison to JOURNEY metaphors, CONFLICT metaphors in the Chicago Tribune data are more prevalent and employed by a composite group of people, including CPS, CTU, teachers, parents, policy scholars, and think tank spokespeople, as well as commenters who hold no stake in the contract negotiations at all. Example (3), taken from the 9/16/2012 article "Parents' power pivotal in walkout: [Both sides tried to sway cadre of angry moms, dads 1]", contains metaphorical instances from CPS parent John Mahr.

(3) “To me, it looked like two strong egos that weren't going to back down," said Mahr, the father of two CPS students. "Nobody wins. Everybody compromises, and the students are the ones that bleed the most."

Apart from the metaphorical depiction of the contract negotiations as a conflict between two opposing sides, what is particularly striking in example (3) is the use of the metaphorical expression bleed. In order to understand why a parent would suddenly employ a metaphor about blood to describe schoolchildren, the reader would have to be conversant about an educational landscape commonly portrayed as explicitly violent. In other words, it appears as common practice for local journalists reporting about education in Chicago to characterise this context as violent and emphasise physical aggressiveness, while at the same time paying little attention to the range of root causes and social factors that might be conducive to violence in the first place. This kind of portrayal is frequent in the reporting of the analysed Chicago Tribune articles, with reporters employing most of the identified CONFLICT metaphors. Example (4), which comes from the 9/9/2012 article, "Strike risky for mayor, union chief: Each could end 
up feeling the heat if there's a lengthy teacher walkout", is in line with this journalistic tendency to frame the issue of education as warfare.

(4) If Chicago teachers go on strike Monday, the walkout would set up a political minefield for both Mayor Rahm Emanuel and Chicago Teachers Union President Karen Lewis, adding the explosive element of a blame game to contract negotiations that already are bighly combustible.

In (4), reporters present Chicago's educational landscape as a minefield including an explosive element and refer to contract negotiations as a blame game that is bighly combustible. These linguistic instantiations of the CONFLICT metaphor are responsible for a vivid and impressive representation of foreseen repercussions of the strike as presented by reporters in their news coverage. In this case, the biased journalistic representation can be related to the fact that such metaphorical expressions are likely to stir readers' emotions and reactions by acting on their fears in order to promote an anti-strike stance.

The strategic use of this graphic and sharp imagery appears as distinctive of the local news coverage of the CUT strike, with many linguistic instantiations of the CONFLICT metaphor being unique to the Chicago Tribune data. These include, among the most telling examples, metaphorical wordings such as beachbeads, blood/y/, bleed, explosive, combative, casualties, defeat, (buman) shield, enemy, blasted, fallout, frontline/s, holding our kids hostage, making a great kill, lashed out, minefield, (clear) victory/ies/ious, troops, enlist, painful, standoff, struggle, threat, harm's way, brink, triumph, weapon, doubleedged sword, (under)cut, sharp words, and targets. This powerful graphic imagery plays on general fears of Chicago residents.

As a way of summarising and highlighting some of the main results emerging from the analysis of metaphorical language usage in the local news coverage, we would like to recap in Table 2 the main pragmatic uses of JOURNEY and CONFLICT metaphors that we identified in the Chicago Tribune. 


JOURNEY metaphors
Emphasise problems/difficulties/efforts in the negoti-
ation process
Show disagreement between the two sides involved in
the negotiation
Express the solidarity among Chicago Teachers and
CTU
Show cohesiveness among Chicago teachers and the
goal-orientation of their actions

CONFLICT metaphors

Portray the educational context as violent and characterised by physical aggressiveness

Provoke strong emotional responses in the readers

Play on fear

Promote an anti-strike stance

Table 2: Main pragmatic uses of Journey and CONFLICT metaphors in the Chicago Tribune

Further comparative observations on the findings will be discussed in the following subsections.

\subsection{Metaphors in International English-language Coverage of the 2012 CTU Strike}

The international readership is not exposed to the same contexts, and thus metaphorical framing is expected to be different from the local readership in Chicago. Accordingly, the data reveal both qualitative and quantitative differences in metaphor usage between the two sets of data, particularly in relation to CONFLICT metaphors.

Since the dataset for the international stories was remarkably smaller than the one for the local news coverage (7,608 vs. 98,200 words), the overall number of metaphors in the international news was possible to count, and totalled 292. As 35 of these metaphors were duplicates (see section 3.3), the international data revealed 257 singular metaphorical expressions. Of these, $21.4 \%(n=55)$ are instantiations of the JOURNEY metaphor, while only $13.6 \%(n=35)$ are examples of the CONFLICT metaphor. A graphic comparison of some numerical data and results concerning metaphor use in the two datasets is presented in Table 3 below. 


\begin{tabular}{lcc}
\hline & $\begin{array}{c}\text { Local news coverage } \\
\text { (representative sample) }\end{array}$ & International news coverage \\
\hline Number of articles & 19 & 19 \\
Word count & 18,481 & 7,608 \\
Percentage of JOURNEY metaphor & $23.3 \%$ & $21.4 \%$ \\
Percentage of CONFLICT metaphors & $35.9 \%$ & $13.6 \%$ \\
\hline
\end{tabular}

Table 3: Numerical comparison of metaphor usage in the two data sets

An interesting example of the JOURNEY metaphor in international papers comes from two sources in the data. Example (5) is identical in the 9/17/2012 China Daily European Edition story "Chicago teachers extend strike, mayor seeks injunction" and in the 9/18/2012 Taranaki Daily News (New Zealand) story "Teachers extend strike".

(5) ... the mayor said he would go to court to block the walkout

The New Zealand Taranaki story only contains the phrase block the walkout, but the China Daily uses that phrase as well as two subsequent phrases, block the labor action and block the strike. It is possible here, then, that in this international coverage, the JouRNEY metaphor of walkout (but not block) is explained in three different ways within the same metaphorical colligation to serve a didactic function for outgroup members (Hallett 2009). Stated differently, reporters of the China Daily, an English-language daily newspaper addressing a Chinese readership, might have felt a need to provide their readers with an explanation of the metaphorical concept of walkout, which led to its textual elaboration in three, distinct and subsequent phrasings (block the walkout, block the labor action, and block the strike). While this explanation can be seen to serve a didactic function in the Chinese context, it would have appeared as pleonastic if used by journalists in New Zealand.

There were also a few instances in the international coverage that are indicative of some highly culturally-specific metaphors that would be expected to be salient to the US readership but not to readers outside of the US. This is exemplified in (6), which is taken from 9/10/2012 article "Chicago Teachers Go on Strike" from The Times of Oman.

(6) ... establishing a recall procedure for teachers who had been laid off as a result of school closings, consolidations and turnarounds.

The word turnarounds, a JOURNEY metaphor, refers to turnaround schools, a controversial American model of school improvement in which designated low-performing 
schools receive an intervention that usually involves, among other measures, the replacement of a substantial proportion of administration and teaching faculty. Counter to our expectations, no explanation or rephrasing of this metaphorical cultural concept was present in the international article addressing a non-American readership.

In terms of mere wording, the international news were found to share a good number of JOURNEY metaphors with the local news. These shared metaphorical expressions comprise backtrack(ed), block, close, course, direction, dragging on, impasse, go on strike, hike, hurdle, lead/led/leading, momentum, move/moved, movement, progress, push/pushes, reach an agreement, turnarounds, walked out, walked off the job, and walkout. There were, however, also instances of the JOURNEY metaphor that were not found in the local news coverage and are thus unique to the international data set. These include nears, distance bimself, walk a fine line, clear(ed) the way, reach a deal, and retreated.

As pointed out above, instantiations of the CONFLICT metaphor comprise less of the metaphor use among international English-language newspapers. One outstanding example of a CONFLICT metaphor in the international coverage comes from the non-wire London paper The Independent, in the 9/18/2012 story, “Obama's man in Chicago in legal bid to stop strikes.”

(7) Anything that associates him with Mr Rahm's perceived assault on the teachers' union could be perilous.

Example (7) is the only case in which the word assault is used in international reporting, the term being arguably the upper limit of aggression in the international data. The same term only appears in the Chicago Tribune data within a quote from CTU leader Karen Lewis (“'The assault on public education started here. It needs to end here,' Lewis said, drawing thunderous applause from the crowd", from 9/12/2012 article "A lot of talk, little progress"). While in both the local and the international news, the word assault is used only once, the term is embedded in diverse types of discourses in the two data sets. In the case of international news, assault remains an isolated allusion to violence. In the local news, to the contrary, the word is part and parcel of a metaphorical depiction of the CTU strike that emphasises physical aggressiveness and plays on readers' fears.

Other expressions of the CONFLICT metaphor exclusive to the international data are, bare-knuckled, losing side, and toe-to-toe. These are certainly metaphors of CONFLICT, with toe-to-toe highlighting the aspect of direct confrontation and bare-knuckled that of fierceness, but overall, they lack the kind of graphic and warlike undertones that characterise CONFLICT metaphors in the local news. 


\subsection{Comparison of Local and Global Frames for Metaphor Use in Media Coverage}

Instantiations of the CONFLICT and JOURNEY metaphors were present in both local and international English-language coverage, but they varied in usage and emotional exploitation (see Hendricks et al. 2018). As explained above, in contrast to the Chicago Tribune reporting, international English-language strike coverage employed far more JOURNEY metaphors than CONFLICT metaphors.

In general, the use of JOURNEY metaphors did not appear as strikingly different in the two data sets, even though some variation was noted. As pointed out above, many metaphorical expressions of JOURNEY overlapped in the two datasets. Interestingly, while backtrack(ed) was shared by both types of papers, only the international papers used the metaphors distance bimself and retreat, both of which are metaphors of regression or moving away.

Overlapping linguistic instantiations of the CONFLICT metaphor across the two datasets are assault, attacking, battle, both/two sides, clear and present danger, confrontation, contentious, dispute, fight/fought, flashpoint, burt, oppose(d), rally, revolt/revolution, and (bracing for a) showdown. As discussed above, these shared terms are contentious, but not as grisly as those employed by only the Chicago Tribune articles (cf. section 4.1). One explanation may be that the reporters for international papers or wire services cannot take for granted that readerships outside of Chicago have the knowledge to understand educators' contract negotiations as necessitating violent and graphic imagery.

Furthermore, that the metaphors in both sets of data are overwhelmingly employed in reporting (rather than in quote or paraphrase) speaks to the power and agency (Semino 2017) of the reporters to shape public discourse (Hallett 2013, Hallett and Hallett 2012). The graphic imagery presented metaphorically in the Chicago Tribune data suggests a degree of emotional manipulation given the localised tensions at this time with respect to school closings, race, politics, and violence in Chicago.

\subsection{Comparison of Metaphor Use in International Wire coverage versus Paper-based Coverage}

As stated above, there are only two international papers that did not employ wire services, The China Daily European Edition, with four stories, and The Independent out of London, with one story. The story from The Independent (9/18/2012) features eleven metaphors, only two in quotes, so the vast majority of metaphor use is by the reporter. The two quoted metaphors are CONFLICT metaphors, from an American; there are no JOURNEY metaphors, and no other patterns are evident in the data. In The China Daily, eighty-one metaphors are used across four stories, twelve of which are quotes. One of 
the quotes is a CONFLICT metaphor, and six are JOURNEY metaphors. China Daily reporter data include ten instances of PERSONIFICATION, nine JOURNEY metaphors, and five CONFLICT metaphors.

For the papers using wire services, the most prevalent metaphors were JOURNEY ( $\mathrm{n}=39$; 5 quoted/paraphrased, 34 reported), CONFLICT ( $\mathrm{n}=25 ; 3$ quoted/paraphrased, 22 reported), and BUILDING ( $\mathrm{n}=16 ; 6$ reported/paraphrased, 10 reported). While there is not enough data analysed here to make a generalisation, the most striking comparison between the wired and non-wired papers is the prevalence of JOURNEY metaphors in the former and the lack of JOURNEY metaphors in the latter.

\section{Implications and Conclusion}

Examining metaphor across English-language news discourse can help uncover deeprooted and self-replicating micro-cultural conceptualisation systems (Kövecses 2005), and - critically - the behavioural consequences potentially resulting from participating in these shared frames (Hendricks et al. 2018). This study examines metaphor use in the same language across different cultural contexts and found one set particularly rife with graphically violent imagery. That the discourse in question relates to the education of children is unarguably troubling.

Goatly (2002) suggests we adopt better metaphors for discourse about education. Semino et al. (2017) examine both violence and JOURNEY metaphors for cancer, and find neither inherently bad, and both as potentially empowering or disempowering. Hendricks et al. (2018) in their work with metaphor and cancer find WAR metaphors particularly unhelpful, as they are often "violent, masculine, and power-based" (268). "Most crucially, the battle metaphor presents lack of recovery as defeat, and hence potentially as a personal failure" (Hendricks et al. 2018, 269). Hendricks et al. suggest adopting more JOURNEY metaphors, which the UK had already taken up with respect to national cancer discourse (Semino et al. 2017).

Ritchie (2013) and Lakoff (2014) reflect on metaphor and framing with respect to a breakdown in commonality of expectations. "When participants in a policy debate understand issues in terms of conflicting or contradictory frames, generated by different metaphors, facts will not resolve the differences" (Ritchie 2013, 109).

The comparison between prevalent metaphor types in English-language education news discourse, and variation within those metaphor types, reveals some linguistic differences in how the same story, the CTU strike, which is embedded in a micro-culture, is reported in English to a local vs. an international readership. Both local and interna- 
tional news were found to rely chiefly on two types of conceptual metaphors, JOURNEY and CONFLICT, with JOURNEY metaphors having a similar share in the two data sets and CONFLICT metaphors being much more frequent in the local coverage.

The fact that local and international news employ JOURNEY metaphors to a comparable extent and also rely on a largely shared metaphorical vocabulary in order to express them, may indicate that this type of metaphorical framing is salient in discourse about any kind of events that unfold over time, i.e. that are conceptualised as a process. In contrast to CONFLICT metaphors, JOURNEY metaphors appear as more emotionally neutral since they capture concepts related to motion or the lack thereof while CONFLICT metaphors evoke a more physical and violent imagery which increases the emotional immediacy of reader responses.

The comparison of the local vs. the international news indeed indicates this difference as, in contrast to JOURNEY metaphors, CONFLICT metaphors are wildly different across the two datasets. Chicago readers are more likely to be emotionally invested in the content of the articles. The violent language used in the local reporting of events, rather than in quoted speech, reflects a framing that emotionally manipulates a readership facing dozens of school closings in Black and Brown communities, which are downplayed or erased in the international coverage, not requiring such graphic imagery. The actual selection of words speaks of a tension between the immediacy of reporting the event in Chicago and the emotional distance characterising the international news. These findings raise the possibility that there is a socially conditioned connection between violence and education in Chicago.

We take the position here that we must assess the prevailing public discourses, including figurative language use, around social concerns such as public education. Then we must surmise the producers, users, and perpetuators of these discourses, raise awareness of the discourses, and actively work to change those that are problematic.

\section{References}

Archakis, Argiris and Villy Tsakona. 2010. “'The Wolf Wakes Up Inside Them, Grows Werewolf Hair and Reveals All Their Bullying': The Representation of Parliamentary Discourse in Greek Newspapers”. Journal of Pragmatics 42: 912-923.

Charteris-Black, Johnathan. 2004. Corpus Approaches to Critical Metaphor Analysis. New York: Palgrave Macmillan.

Charteris-Black, Johnathan. 2011. Politician and Rhetoric. The Persuasive Power of Metaphor, 2nd ed., Basingstoke: Palgrave Macmillan. 
Charteris-Black, Johnathan. 2017. Fire Metaphors: Discourses of Awe and Authority. London: Bloomsbury.

Cockcroft, Robert and Susan Cockcroft. 2014. Persuading People. An Introduction to Rhetoric, 3rd ed., Basingstoke: Palgrave Macmillan.

Demmen, Jane, Elena Semino, Zsófia Demjén et al. 2015. "A Computer-Assisted Study of the Use of Violence Metaphors for Cancer and End of Life by Patients, Family Carers and Health Professionals”. International Journal of Corpus Linguistics 20(2): 205-231.

Downing, John D. H., Denis McQuail, Philip Schlesinger and Ellen Wartella (eds.). 2004. Handbook of Media Studies. London: Sage.

Entman, Robert M. 1993. "Framing: Toward Clarification of a Fractured Paradigm”. Journal of Communication 43(4): 51-58.

Ezeifeka, Chinwe Roseann. 2013. "Strategic Use of Metaphor in Nigerian Newspaper Reports: A Critical Perspective”. Critical Approaches to Discourse Analysis across Disciplines 6(2): 174192.

Fairclough, Norman. 1995. Critical Discourse Analysis: The Critical Study of Language. Essex: Longman.

Fairclough, Norman. 1999. "Global Capitalism and Critical Awareness of Language”. Language Awareness 8(2): 71-83.

Fairhurst, Gail T. and Robert A. Sarr. 1996. The Art of Framing. Managing the Language of Leadership. San Francisco, CA: Jossey-Bass.

Flusberg, Stephen J., Tennie Matlock and Paul H. Thibodeau. 2018. "War Metaphors in Public Discourse". Metaphor and Symbol 33(1): 1-18.

Fridolfsson, Charlotte. 2008. "Political Protest and Metaphor". In Political Language and Metaphor. Interpreting and Changing the World, edited by Terrell Carver and Jernej Pikalo, 132-148. London: Routledge.

Gamson, William A. 1992. Talking Politics. Cambridge: Cambridge University Press.

Gamson, William and André Modigliani. 1989. "Media Discourse and Public Opinion on Nuclear Power: A Constructionist Approach”. American Journal of Sociology 95(1): 1-37.

Goatly, Andrew. 2002. "Conflicting Metaphors in the Hong Kong Special Administrative Region Educational Reform Proposals”. Metaphor and Symbol 17(4): 263-294.

Hallett, Jill "'Serve it Up in a Barfi': Codeswitching Patterns in Indian and Diasporic Newspapers.” Paper presented at the 31st Annual All-India Conference of Linguists, Hyderabad, India December 15-17, 2009.

Hallett, Jill. 2013. “Constructing 'Remorse': The Preparation of Social Discourses for Public Consumption”. Text E Talk 33(2): 189-212.

Hallett, Jill and Richard Hallett. 2012. "Metaphors and Topoi of H1N1 (Swine Flu) Political Cartoons: A Cross-Cultural Analysis”. In Linguistics and the Study of Comics, edited by Frank Bramlett, 59-91. New York: Palgrave MacMillan.

Hart, Christopher. 2014a. "Construal Operations in Online Press Reports of Political Protests". In Contemporary Critical Discourse Studies, edited by Christopher Hart and Piotr Cap, 167188. London: Bloomsbury. 
Hart, Christopher. 2014b. Discourse, Grammar and Ideology: Functional and Cognitive Perspectives. London: Bloomsbury.

Hart, Christopher. 2017. "Metaphor and Intertextuality in Media Framings of the (1984-1985) British Miners' Strike: A Multimodal Analysis”. Discourse E̊ Communication 11 (1): 3-30.

Hendricks, Rose K., Zsófia Demjén, Elena Semino and Lera Boroditsky. 2018. "Emotional Implications of Metaphor: Consequences of Metaphor Framing for Mindset about Cancer”. Metaphor and Symbol 33 (4): 267-279.

Johnson, Eric. 2007. "Sculpting Public Opinion: Understanding the (Mis)use of Metaphor in the Media”. In Cognitive Linguistics in Critical Discourse Analysis: Application and Theory, edited by Christopher Hart and Dominik Lukeš, 28-56. Newcastle: Cambridge Scholars Publishing.

Koller, Veronika. 2005. "Critical Discourse Analysis and Social Cognition: Evidence from Business Media Discourse”. Discourse E' Society 16 (2): 199-224.

Kövecses, Zoltan. 2005. Metaphor in Culture: Universality and Variation. Cambridge: Cambridge University Press.

Lakoff, George. 1996. Moral Politics: What Conservatives Know that Liberals Don't. Chicago: University of Chicago Press.

Lakoff, George. 2014. The All New Don't Think of an Elephant!: Know Your Values and Frame the Debate. White River Junction, Vermont: Chelsea Green Publishing.

Lakoff, George and Mark Johnson. 1980. Metaphors We Live By. Chicago: University of Chicago Press.

McCombs, Maxwell E. 1997. “Building Consensus: The News Media’s Agenda-Setting Roles”. Political Communication 14: 433-443.

McCombs, Maxwell E. and Daniel L. Shaw. 1972. "The Agenda-Setting Function of Mass Media”. Public Opinion Quarterly 36: 176-187.

Medhurst, Martin J. and Michael DeSousa. 1981. "Political Cartoons as Rhetorical Form: A Taxonomy of Graphic Discourse”. Communication Monographs 48: 197-236.

Pragglejaz Group. 2007. "A Practical and Flexible Method for Identifying Metaphorically-Used Words in Discourse”. Metaphor and Symbol 22, 1-39.

Reese, Stephen D., Oscar H. Gandy and August E. Grant (eds.). 2003. Framing Public Life: Perspectives on Media and Our Understanding of the Social World. Mahwah, NJ: Lawrence Erlbaum Associates.

Semino, Elena. 2008. Metaphor in Discourse. Cambridge: Cambridge University Press.

Semino, Elena, Zsófia Demjén, Jane Demmen, Veronika Koller, Sheila Payne, Andrew Hardie and Paul Rayson. 2017. “The Online Use of 'Violence' and 'Journey' Metaphors by Cancer Patients, as Compared with Health Professionals: A Mixed Methods Study”. BMJ Supportive and Palliative Care 7 (1): 60-66. Van Gorp, Baldwin. 2005. "Where is the Frame? Victims and Intruders in the Belgian Press Coverage of the Asylum Issue". European Journal of Communication 20 (4): 485-508.

Weaver, David H. 2007. “Thoughts on Agenda-Setting, Framing and Priming”. Journal of Communication 57: 142-147.

Wodak, Ruth. 2005. "What CDA is about?". In Methods of Critical Discourse Analysis, edited by Ruth Wodak \& Michael Meyer, 1-13. London: Sage. 